\title{
Human Lateralization, Maternal Effects and Neurodevelopmental Disorders
}

\author{
Gianluca Malatesta*, Daniele Marzoli, Giulia Prete and Luca Tommasi \\ Department of Psychological, Health and Territorial Sciences, University "G. d'Annunzio" of Chieti and Pescara, Chieti, Italy
}

\section{OPEN ACCESS}

Edited by:

Lorenzo More

University of Central Lancashire, United Kingdom

Reviewed by:

Julian Packheiser,

Ruhr University Bochum, Germany

Lesley J. Rogers,

University of New England, Australia

${ }^{*}$ Correspondence:

Gianluca Malatesta

gianluca.malatesta@unich.it

Specialty section:

This article was submitted to

Pathological Conditions,

a section of the journal

Frontiers in Behavioral Neuroscience

Received: 16 February 2021 Accepted: 04 March 2021

Published: 22 March 2021

Citation:

Malatesta G, Marzoli D, Prete G and Tommasi L (2021) Human

Lateralization, Maternal Effects and

Neurodevelopmental Disorders.

Front. Behav. Neurosci. 15:668520.

doi: 10.3389/fnbeh.2021.668520
In humans, behavioral laterality and hemispheric asymmetries are part of a complex biobehavioral system in which genetic factors have been repeatedly proposed as developmental determinants of both phenomena. However, no model solely based on genetic factors has proven conclusive, pushing towards the inclusion of environmental and epigenetic factors into the system. Moreover, it should be pointed out that epigenetic modulation might also account for why certain genes are expressed differently in parents and offspring. Here, we suggest the existence of a sensitive period in early postnatal development, during which the exposure to postural and motor lateral biases, expressed in interactive sensorimotor coordination with the caregiver, canalizes hemispheric lateralization in the "typical" direction. Despite newborns and infants showing their own inherent asymmetries, the canalizing effect of the interactive context owes most to adult caregivers (usually the mother), whose infant-directed lateralized behavior might have been specifically selected for as a population-level trait, functional to confer fitness to offspring. In particular, the case of the left-cradling bias (LCB; i.e., the population-level predisposition of mothers to hold their infants on the left side) represents an instance of behavioral trait exhibiting heritability along the maternal line, although no genetic investigation has been carried out so far. Recent evidence, moreover, seems to suggest that the reduction of this asymmetry is related to several unfavorable conditions, including neurodevelopmental disorders. Future studies are warranted to understand whether and how genetic and epigenetic factors affect the lateralization of early mother-infant interaction and the proneness of the offspring to neurodevelopmental disorders.

Keywords: laterality, hemispheric asymmetry, mother-infant interaction, cradling-side bias, behavioral epigenetics, autism spectrum disorders

\section{BEHAVIORAL EPIGENETICS AND THE DEVELOPMENT OF LATERALIZATION}

Studies on lateralization have progressed at a remarkable pace in recent decades, gathering multiple levels belonging to different disciplines and traditions of research. Neural, behavioral and genetic aspects of asymmetries are becoming more and more connected to each other in the all-encompassing framework of biological evolution. Theoretical models suggest that interactive behaviors are key to the evolution of population-level lateral biases (e.g., Ghirlanda and Vallortigara, 2004): a stable equilibrium in the asymmetrical distribution of lateralized behavioral phenotypes of a 
given species might be reached through the fitness contribution of both antagonistic and synergistic interactions occurring among its members (Ghirlanda et al., 2009). Empirical evidence seems also to suggest that early development is a crucial context in which synergistic interactions affect lateralization (Karenina et al., 2017). However, only rarely evolutionary accounts of lateralization including developmental plasticity as a determining factor have been suggested (e.g., see Michel et al., 2018).

In humans, the ontogeny of lateralization emerges from the multifaceted interaction between genetic and environmental factors that have not been understood in full detail (Güntürkün and Ocklenburg, 2017). Structural asymmetries of the brain are but a small fraction of the Bauplan of neural lateralization-the largest part being expressed in the form of functional asymmetries - and they consist in the allocation of different roles to two structurally similar brain hemispheres (Corballis, 2017). Functional asymmetries are ubiquitous in the nervous system especially in the neocortex, and they emerge in many behavioral and mental functions, including action (Guiard, 1987; Serrien and Sovijärvi-Spapé, 2015), imagination (Marzoli et al., 2011a,b, 2013, 2017a; Prete et al., 2016b; Altamura et al., 2020), perception (Marzoli and Tommasi, 2009; Brancucci and Tommasi, 2011; Prete et al., 2015d, 2018b; Prete and Tommasi, 2018), emotion (Prete et al., 2014a, 2015a,c; Wyczesany et al., 2018), attention (Yamaguchi et al., 2000; Chen and Spence, 2017) and memory (Iidaka et al., 2000; Penolazzi et al., 2010; D'Anselmo et al., 2016). Language can be considered the most emblematic case of functional asymmetry, also because the history of discoveries on brain lateralization (and localization) began precisely with aphasia studies (Leblanc, 2017). Nevertheless, it must be noted that motor functions deserve a special place in this list, particularly because of the peculiar status of handedness as a function that is lateralized both behaviorally and neurologically from early childhood (Bondi et al., 2020): around 90\% of humans show a preference for using the right hand, which is controlled by the left brain hemisphere (McManus, 2002; Tommasi, 2009). Additionally, footedness should also be granted a special position in the field of human laterality, having been shown to share similarities with handedness both in behavioral and neuropsychological terms, and to be less influenced by cultural and social factors than handedness (Elias and Bryden, 1998; Tran et al., 2014; Packheiser et al., 2020a,c). Population-level motor asymmetries which seem to be precursors of handedness are observed already during fetal life (Hepper et al., 1990; Hepper, 2013; see also Baciadonna et al., 2010 for analogous early predictors of limb laterality in a non-human species), speaking in favor of a substantial genetic contribution. In this regard, the search for genetic factors of human functional lateralization has been characterized by single- or multiple-gene theories aimed to explain handedness, and continues nowadays within molecular genetics studies addressed to the identification of specific loci (Cuellar-Partida et al., 2021). Interestingly, these studies also suggest a partly common ground among genetic variants influencing the development of brain functional laterality and the emergence of neurodevelopmental disorders (Wiberg et al., 2019). However, no evidence has proven strong enough to exactly explain the statistical frequencies of hand preference observed in families (Medland et al., 2009; McManus et al., 2013; Armour et al., 2014). Environmental factors have been therefore implicated, from the effect of hormones (Geschwind and Galaburda, 1985; Berretz et al., 2020) and fetus position in utero (Previc, 1991), to the visual experience of own and others' hands during early infancy (Michel and Harkins, 1986; Fagard and Lemoine, 2006). Michel et al. (2018) suggested that the development of lateralization begins prenatally, and progresses postnatally as a head orientation preference, predominantly right-biased in infants (Michel and Harkins, 1986). Such an early rightward postural asymmetry would have the effect of placing their right hand in their visual field more than their left hand, thus causing cascading feedback-based proprioceptive effects during movement, possibly facilitating the gradual emergence of right-handedness. This suggestion was also confirmed by the observation of children with congenital muscular torticollis, whose restricted early visual experience affected the later development of handedness (Ocklenburg et al., 2010). On the other hand, right-handedness might also be fostered by children imitating adult's manual preferences (Fagard and Lemoine, 2006). Similar mechanisms might be involved not only in the development of handedness, but also in the attentional bias toward the right side of others' body observed in both right- and left-handers (Marzoli et al., 2015, 2017a,b, 2019; Lucafò et al., 2016, 2021; see also Marzoli et al., 2014), which in turn could account for the left-handers' advantage in fighting and sports (e.g., Groothuis et al., 2013). Although the relative weight of genetic and environmental determinants of handedness has not been established yet, epigenetic effects have been hypothesized at both the molecular (Leach et al., 2014) and the behavioral level (Schmitz et al., 2017), and the same should be true for other instances of functional asymmetries.

In addition to prenatal processes occurring in utero (e.g., Ocklenburg et al., 2017), behavioral epigenetics could play a major role during postnatal life, specifically because of parental care: humans, as many mammalian species, are indeed characterized by altriciality, that is an extended period after birth during which the newborn is helpless and depends on external sources (i.e., adults) for survival (Gubernick, 2013). This means that the social and behavioral environment is crucial-through an extraordinarily complex matrix of variables-for development. This "epigenetic niche" exerts an effect on the offspring's endophenotype, bringing about the expression of the genes in an environment shared with the caregivers. Importantly, the social bonding between parent and offspring is an environment in and of itself, and since the attachment behavioral system is the predisposed motivational structure that brings the infant and the mother to seek proximity to each other (Simpson and Belsky, 2008; Norholt, 2020), it may well constitute a very powerful context for the development of laterality. In this frame, lateralization research might take advantage of an important example of epigenetic niche: in the last decades, in fact, "cradling behavior" emerged as a specific case of lateralized social behavior involving parent (in particular the mother) and child, potentially modulating the development of hemispheric lateralization (Packheiser et al., 2019b). 


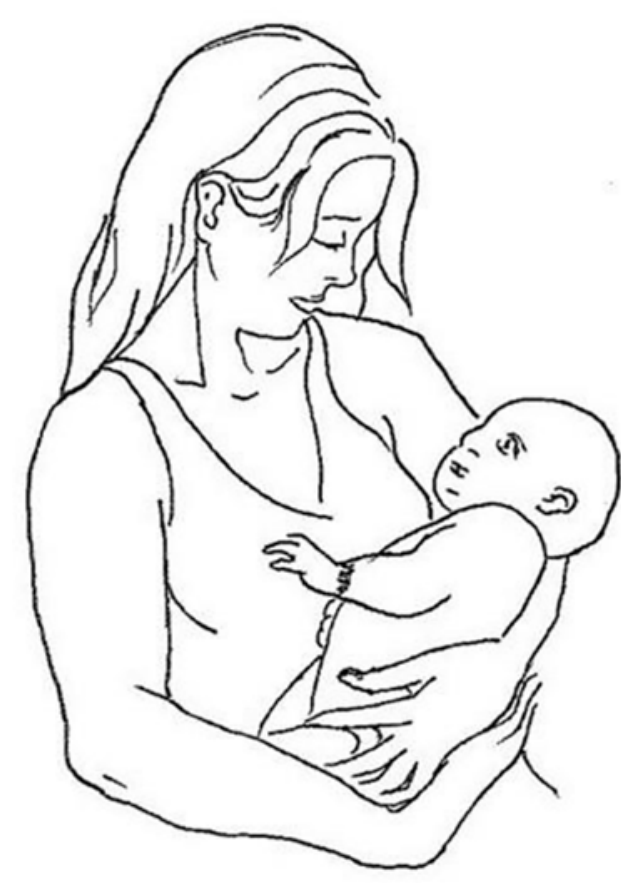

FIGURE 1 | An example of left-cradling bias (LCB).

\section{CRADLING-SIDE BIAS AS MATERNAL EFFECT}

Cradling behavior has been consistently reported as left-lateralized at the population level, especially in women (65-70\% of women cradle infants to the left of their body midline; see Figure 1; Packheiser et al., 2019b), and the bias has been causally linked to the development of the right hemisphere (Manning and Chamberlain, 1991; Harris et al., 2001; Bourne and Todd, 2004).

Indeed, it has been shown that the left-cradling bias (LCB) sets the postural conditions that facilitate an optimal emotional attunement between adult and infant because the right brain hemispheres of both are predominantly engaged during interactions in which the infant is held on the left side of the adult (Harris et al., 2010). This bias can be supposed to provide the infant with what Gilbert Gottlieb called "experiential canalization" (Gottlieb, 1991), a form of supervised narrowing of experience that the infant is predisposed to receive during a precise period. This is supported by a great amount of evidence: (i) in adults, cradling behavior is more strongly left-biased during the first year of life of the child and then declines in strength (Dagenbach et al., 1988); (ii) adults are selectively biased to the left when cradling (or even imagining cradling) infants or dolls rather than when holding or carrying inanimate objects (Harris et al., 2000); (iii) females are significantly more left-biased than males (Packheiser et al., 2019b); and (iv) the LCB seems to be transmitted from mother to daughter as a sex-linked inherited trait (Manning and Denman, 1994). In light of this evidence, it could be argued that the adult genes encode for the presence of an "obligatory" behavior in the motherinfant attachment during a "sensitive period" of the infant's development, and for a population-level predisposition to implement it asymmetrically on the left side. The experiential side of the story would consist of the interaction and sensorimotor coordination between adults and infants arising from the LCB. From this perspective, such an experience might modulate epigenetically the direction of the development of typical brain lateralization, triggered and scaffolded by the parent or the caregiver. Interestingly, the stronger LCB in females and the related maternal intergenerational transmission might be consistent with epigenetic studies indicating that certain genes are expressed differently in parents and offspring, as occurs in the case of differential parental imprinting (e.g., maternally derived duplications of a specific portion of chromosome 15 lead to an increased risk of autism and schizophrenia more than analogous paternally derived duplications; Cook et al., 1997; Isles et al., 2016).

A further aspect of this epigenetic view is that the LCB could be advantageous from an evolutionary perspective, because it is correlated to fitness-related traits in mothers, and possibly in children. For instance, research has shown that the correlates of cradling are indirectly evident when comparing women showing different degrees of left (typical) or right (atypical) cradling (Malatesta et al., 2019a,b, 2020b), bringing to the hypothesis that an atypical trajectory in maternal cradling might be one early sign of interference of dyadic socio-emotional communication, and thus of potential neurodevelopmental dysfunctions (Malatesta et al., 2020a,d). The fact that this left-sided population-level asymmetry goes in the direction opposite to that of a majority of right-handers, moreover, provides an important hint that it possibly attained a special functional status during evolution, and this speculation is further supported by the presence of an LCB also in left-handers. In this regard, it should be noted that the bias is detectable also in left-handers, indicating that it does not depend upon the fact that holding on the left would free the adult's dominant hand (Packheiser et al., $2019 b$ ). As such, the epigenetic niche represented by the mother cradling the baby would consist, in strictly biological terms, in a genuine maternal effect (Maestripieri and Mateo, 2009). This is supported by evidence of sex- and side-dependent effects of social perception obtained in previous works-for instance, the fact that the well-known left-face bias seems to be stronger for female faces, suggesting a greater sensitivity for the female face in the right hemisphere (Parente and Tommasi, 2008; Prete et al., 2016a, 2017), and the fact that females showing an LCB are more likely attracted by the left rather than right profile of a baby compared to females showing the opposite bias (Malatesta et al., 2020c).

Among the main explanations suggested for the LCB, the right-hemisphere hypothesis-the most accredited one today-revolves around the interaction and the socio-emotional information exchanged between the cradling and the cradled individual (Manning and Chamberlain, 1991; Harris et al., 2001; Bourne and Todd, 2004; for similar considerations in non-human species see Giljov et al., 2018). According to this 
hypothesis, the right hemisphere should be mainly involved in emotional processing (Levy et al., 1983; Gainotti, 2012; Prete et al., 2014b, 2015b, 2018a), leading to a left hemibody and hemiface superiority in both the expression and the encoding of emotions. Similarly, evidence confirming the right-hemisphere hypothesis has been collected also for other lateralized social behaviors such as embracing and kissing (Ocklenburg et al., 2018; Packheiser et al., 2019a, 2020b). Therefore, cradling might represent a specific interactional framework benefiting both the mother and the infant, whose lateralization has unlikely been left to chance by evolutionary pressures. From the mother's point of view, the left-side positioning might facilitate the monitoring of her infant's well-being cues through her left visual and auditory fields, which project more directly to her right hemisphere (i.e., the one more involved in social and emotional processing; Brancucci et al., 2009; Prete et al., 2020a,b). Consistently, left-cradling individuals exhibit a stronger leftward bias for the processing of emotions from faces (Harris et al., 2001, 2010; Bourne and Todd, 2004). Moreover, the discovery of a preference for the left profile of infants in women showing a left-cradling bias (Malatesta et al., 2020c) suggests that a further adaptive function of the LCB might consist in a facilitated monitoring of the left hemiface of the infant, which is considered more expressive (Mendolia and Kleck, 1991) and whose emotional valence is identified more accurately, especially when a negative emotion is displayed (Kleck and Mendolia, 1990). Similarly, the LCB might expose the right hemisphere of children to the more expressive side of the mother's face (Hendriks et al., 2011). It is also possible to suppose that this double interaction (Table 1) gave an important advantage to both mothers and infants during the evolution by fostering typical neurodevelopment in the cradled infants.

In this regard, it has been shown that individuals cradled on the mother's right side during infancy showed a significant decrease of the typical left bias for emotional faces compared to left-cradled individuals, suggesting that mothers' cradling laterality has crucial outcomes on their children's development of socio-emotional abilities, such as the ability to perceive facial emotions later in life (Vervloed et al., 2011).

\section{CRADLING BEHAVIOR AND NEURODEVELOPMENTAL DISORDERS}

The role of the LCB in facilitating emotional communication is supported by findings suggesting that a reduction or inversion of the typical cradling lateralization is associated with several factors that might interfere with the quality of the mother-infant

TABLE 1 | Table summarizing the double interaction of left-cradling bias (LCB) functions from the perspective of mother and infant.

\begin{tabular}{ll}
\hline Mother & Infant \\
\hline $\begin{array}{l}\text { Monitoring the infant through the left } \\
\text { visual and auditory fields. }\end{array}$ & Exposure to the mother's left-hemiface. \\
Exposure to the infant's left-hemiface. & $\begin{array}{l}\text { Monitoring the mother through the left } \\
\text { visual and auditory fields. }\end{array}$
\end{tabular}

relationship and be a sign of a lack of wellbeing in the cradling woman. In previous studies, we showed that a reduction of the LCB is related to: (i) reduced empathy and increased depressive symptoms in mothers (Malatesta et al., 2019b); (ii) non-optimal patterns of attachment styles in females (Malatesta et al., 2019a); and (iii) prejudiced attitudes towards the cradled individual's ethnic group in females (Malatesta et al., 2020b). Similarly, the negative association between atypical (right) cradling and the quality of the mother-infant relationship seems to be confirmed by the fact that stress and negative affective states reduce the leftward asymmetry (Bogren, 1984; Weatherill et al., 2004; Suter et al., 2007, 2011; Reissland et al., 2009; Scola et al., 2013; Boulinguez-Ambroise et al., 2020; Pileggi et al., 2020). Furthermore, a link between this population-level bias and the later development of a typical cognitive and socio-emotional functioning has been suggested by recent findings associating developmental disorders-such as autism spectrum disorder (ASD) - and atypical patterns of lateralization in cradling (Jones, 2014; Pileggi et al., 2015; Forrester et al., 2019, 2020; Herdien et al., 2020; Malatesta et al., 2020a,d). This link is also highlighted by evidence unveiling that ASD constitutes a group of neurodevelopmental disorders that, besides entailing chronic and severe impairment in socio-communicative and empathic relationships, are also characterized by an early hypolateralization of brain functions (e.g., Escalante-Mead et al., 2003; Stroganova et al., 2007), including a reduced left bias for faces (Ashwin et al., 2005; Dundas et al., 2012). Furthermore, given that parents of children with ASD exhibit autistic traits to a greater extent compared with controls (Bishop et al., 2004; Ruta et al., 2012; Bora et al., 2017) and given that autistic traits in adults are associated with a reduced LCB (Fleva and Khan, 2015), we have hypothesized an association between reduced left-cradling preference in mothers and later diagnosis of ASD in children (Malatesta et al., 2020a,d). This perspective is in line with research on other forms of systematic deviation from the typical behavioral lateralization such as left-handedness. For example, although the issue is still debated (McManus, 2019), left-handedness has been related to several impairments (e.g., in cognitive abilities such as intelligence and spatial abilities; Gibson, 1973; Johnston et al., 2009; Nicholls et al., 2010; Papadatou-Pastou and Tomprou, 2015; Somers et al., 2015) and has been considered as a cue of reduced fitness (e.g., for evidence in favor of a relation between reduced right-handedness and decreased academic and socioeconomic success see Deary et al., 2007; Strenze, 2007), along with other negative predictors of fitness (e.g., fluctuating asymmetries such as ear, digit, or wrist asymmetries; Manning et al., 1997) which have been related to atypical brain asymmetries (Thoma et al., 2002) and left-handedness itself (Kobyliansky and Micle, 1986).

\section{CONCLUSION}

We propose the idea that human caregivers play a canalizing role during a sensitive period of developmental plasticity via their own lateralized motor patterns. These would give rise in the infant to lateralized experiences in multiple sensory 
modalities, due to the bidirectional nature of interactive behavior at very close contact. Of all biases, the case of cradling would be extremely interesting to examine with such an approach because its obligatory and simple nature could qualify it as a major epigenetic determinant of neural lateralization. Moreover, the LCB could be the access point to a wider pattern of lateralized adult-infant interactive and social behaviors (embracing, caressing, kissing, cuddling, tickling, whispering, et cetera) acting as epigenetic niches for typical development. Further studies are needed to establish associations among the lateralized experience provided by those interactive behaviors, hemispheric asymmetries, and motor, cognitive and socioemotional development. Given the role of the attachment system as a regulator of proximity seeking (Simpson and Belsky, 2008), and the previous evidence linking the cradling side to attachment in adults (Malatesta et al., 2019a), a major target should be the search for links among the observed patterns of infant attachment and the aforementioned motor, neural and developmental variables. Furthermore, cradling behavior has coevolved with the infant's proclivity to actively cling onto the caregiver (Berecz et al., 2020), and being held or carried on the left or the right side of the adult's body imposes complementary degrees of freedom on the infant's left and right upper limbs. Thus, a direct effect of adult-infant postural laterality is expected to be manifested in the differential use of arms and hands by the infant. More specifically, it is possible to predict that left-sided cradling favors the development of right-handedness in the infant, an effect already assessed in nonhuman primates (Hopkins, 2004) and investigated only partially in humans (Scola and Vauclair, 2010).

Based on the state-of-the-art on the cradling-, embracingand kissing-side bias research, a better understanding of the adaptive role of these behavioral asymmetries appear desirable to verify their potential function. For example, although research carried out since 1960 has examined the possible correlations between typical/atypical cradling lateralization and several variables in different populations, we do not know much about its association with typical brain organization

\section{REFERENCES}

Altamura, M., Prete, G., Elia, A., Angelini, E., Padalino, F. A., Bellomo, A., et al. (2020). Do patients with hallucinations imagine speech right? Neuropsychologia 146:107567. doi: 10.1016/j.neuropsychologia.2020. 107567

Armour, J. A. L., Davison, A., and McManus, I. C. (2014). Genome-wide association study of handedness excludes simple genetic models. Heredity 112, 221-225. doi: 10.1038/hdy.2013.93

Ashwin, C., Wheelwright, S., and Baron-Cohen, S. (2005). Laterality biases to chimeric faces in Asperger syndrome: what is 'right' about face-processing? J. Autism Dev. Disord. 35, 183-196. doi: 10.1007/s10803-004-1997-3

Baciadonna, L., Zucca, P., and Tommasi, L. (2010). Posture in ovo as a precursor of footedness in ostriches (Struthio camelus). Behav. Processes 83, 130-133. doi: 10.1016/j.beproc.2009.09.004

Berecz, B., Cyrille, M., Casselbrant, U., Oleksak, S., and Norholt, H. (2020). Carrying human infants-an evolutionary heritage. Infant Behav. Dev. 60:101460. doi: 10.1016/j.infbeh.2020.101460 and increased fitness, and the possible outcomes on the offspring of being cradled on the left or the right during infanthood. Compared to other asymmetrical patterns of brain organization (e.g., handedness), cradling behavior necessarily involves the joint participation of two individuals: one cradling and another being cradled. In this regard, it is plausible that lateral cradling preferences are strongly associated with affective functioning, which is known to be strongly impaired in disorders such as autism, schizophrenia, and alexithymia (Tordjman, 2008).

To conclude, this perspective aims to encourage the detailed study of the nature and effects of the motor and sensory lateral biases expressed in the context of adult-infant interactive behavior. Due to the difficulties in directly manipulating such a dyadic interaction to show possible causal effects in humans, the involvement of animal models might be a useful approach (Manning et al., 1994; Karenina et al., 2017; Giljov et al., 2018; Boulinguez-Ambroise et al., 2020). Moreover, the lateral preference stability over time has received little attention to date, with conflicting findings (Dagenbach et al., 1988; Manning, 1991; Scola et al., 2013; Todd and Banerjee, 2016; Malatesta et al., 2020a). Therefore, the dynamics and spatiotemporal progression of the active and passive biases of the dyad over time should be investigated with a microgenetic approach, and their directionality and strength should be associated with longitudinal assessments of hemispheric asymmetries, cognitive development, and the pattern of attachment between parent and infant.

\section{DATA AVAILABILITY STATEMENT}

The original contributions presented in the study are included in the article, further inquiries can be directed to the corresponding author.

\section{AUTHOR CONTRIBUTIONS}

All authors listed have made a substantial, direct and intellectual contribution to the work, and approved it for publication.

Berretz, G., Wolf, O. T., Güntürkün, O., and Ocklenburg, S. (2020). Atypical lateralization in neurodevelopmental and psychiatric disorders: what is the role of stress? Cortex 125, 215-232. doi: 10.1016/j.cortex.2019. 12.019

Bishop, D. V. M., Maybery, M., Maley, A., Wong, D., Hill, W., and Hallmayer, J. (2004). Using self-report to identify the broad phenotype in parents of children with autistic spectrum disorders: a study using the autism-spectrum quotient. J. Child Psychol. Psychiatry 45, 1431-1436. doi: 10.1111/j.1469-7610.2004. 00849.x

Bogren, L. Y. (1984). Side preference in women and men when holding their newborn child: psychological background. Acta Psychiatr. Scand. 69, 13-23. doi: 10.1111/j.1600-0447.1984.tb04512.x

Bondi, D., Prete, G., Malatesta, G., and Robazza, C. (2020). Laterality in children: evidence for task-dependent lateralization of motor functions. Int. J. Environ. Res. Public Health 17:6705. doi: 10.3390/ijerph171 86705

Bora, E., Ayd $\imath$ n, A., Saraç, T., Kadak, M. T., and Köse, S. (2017). Heterogeneity of subclinical autistic traits among parents of children with autism spectrum 
disorder: identifying the broader autism phenotype with a data-driven method. Autism Res. 10, 321-326. doi: 10.1002/aur.1661

Boulinguez-Ambroise, G., Pouydebat, E., Disarbois, É., and Meguerditchian, A. (2020). Human-like maternal left-cradling bias in monkeys is altered by social pressure. Sci. Rep. 10:11036. doi: 10.1038/s41598-020-68020-3

Bourne, V. J., and Todd, B. K. (2004). When left means right: an explanation of the left cradling bias in terms of right hemisphere specializations. Dev. Sci. 7, 19-24. doi: 10.1111/j.1467-7687.2004.00318.x

Brancucci, A., Lucci, G., Mazzatenta, A., and Tommasi, L. (2009). Asymmetries of the human social brain in the visual, auditory and chemical modalities. Philos. Trans. R. Soc. Lond. B Biol. Sci. 364, 895-914. doi: 10.1098/rstb.2008.0279

Brancucci, A., and Tommasi, L. (2011). "Binaural rivalry": dichotic listening as a tool for the investigation of the neural correlate of consciousness. Brain Cogn. 76, 218-224. doi: 10.1016/j.bandc.2011.02.007

Chen, Y.-C., and Spence, C. (2017). Hemispheric asymmetry: Looking for a novel signature of the modulation of spatial attention in multisensory processing. Psychon. Bull. Rev. 24, 690-707. doi: 10.3758/s13423-016-1154-y

Cook, E. H. Jr., Lindgren, V., Leventhal, B. L., Courchesne, R., Lincoln, A., Shulman, C., et al. (1997). Autism or atypical autism in maternally but not paternally derived proximal 15q duplication. Am. J. Hum. Genet. 60, 928-934. doi: 10.1016/j.bbi.2019.07.025

Corballis, M. C. (2017). The evolution of lateralized brain circuits. Front. Psychol. 8:1021. doi: 10.3389/fpsyg.2017.01021

Cuellar-Partida, G., Tung, J. Y., Eriksson, N., Albrecht, E., Aliev, F., Andreassen, O. A., et al. (2021). Genome-wide association study identifies 48 common genetic variants associated with handedness. Nat. Hum. Behav. 5, 59-70. doi: 10.1038/s41562-020-00956-y

D'Anselmo, A., Marzoli, D., and Brancucci, A. (2016). The influence of memory and attention on the ear advantage in dichotic listening. Hear. Res. 342, 144-149. doi: 10.1016/j.heares.2016.10.012

Dagenbach, D., Harris, L. J., and Fitzgerald, H. E. (1988). A longitudinal study of lateral biases in Parents' cradling and holding of infants. Infant Ment. Health J. 9, 218-234. doi: 10.1002/1097-0355(198823)9:3<18::aid-imhj2280090305>3.0. co;2-d

Deary, I. J., Strand, S., Smith, P., and Fernandes, C. (2007). Intelligence and educational achievement. Intelligence 35, 13-21. doi: 10.1016/j.intell.2006. 02.001

Dundas, E. M., Best, C. A., Minshew, N. J., and Strauss, M. S. (2012). A lack of left visual field bias when individuals with autism process faces. J. Autism Dev. Disord. 6, 1104-1111. doi: 10.1007/s10803-011-1354-2

Elias, L. J., and Bryden, M. P. (1998). Footedness is a better predictor of language lateralisation than handedness. Laterality 3, 41-51. doi: 10.1080/713754287

Escalante-Mead, P. R., Minshew, N. J., and Sweeney, J. A. (2003). Abnormal brain lateralization in high-functioning autism. J. Autism Dev. Disord. 33, 539-543. doi: 10.1023/a:1025887713788

Fagard, J., and Lemoine, C. (2006). The role of imitation in the stabilization of handedness during infancy. J. Integr. Neurosci. 5, 519-533. doi: $10.1142 / \mathrm{s} 0219635206001343$

Fleva, E., and Khan, A. (2015). An examination of the leftward cradling bias among typically developing adults high on autistic traits. Laterality 20, 711-722. doi: 10.1080/1357650X.2015.1046881

Forrester, G. S., Davis, R., Malatesta, G., and Todd, B. K. (2020). Evolutionary motor biases and cognition in children with and without autism. Sci. Rep. 10:17385. doi: 10.1038/s41598-020-74224-4

Forrester, G. S., Davis, R., Mareschal, D., Malatesta, G., and Todd, B. K. (2019). The left cradling bias: an evolutionary facilitator of social cognition? Cortex 118, 116-131. doi: 10.1016/j.cortex.2018.05.011

Gainotti, G. (2012). Unconscious processing of emotions and the right hemisphere. Neuropsychologia 50, 205-218. doi: 10.1016/j.neuropsychologia. 2011.12.005

Geschwind, N., and Galaburda, A. M. (1985). Cerebral lateralization. Biological mechanisms, associations, and pathology: I. A hypothesis and a program for research. Arch. Neurol. 42, 428-459. doi: 10.1001/archneur.1985. 04060050026008

Ghirlanda, S., Frasnelli, E., and Vallortigara, G. (2009). Intraspecific competition and coordination in the evolution of lateralization. Philos. Trans. R. Soc. Lond. B Biol. Sci. 364, 861-866. doi: 10.1098/rstb. 2008.0227
Ghirlanda, S., and Vallortigara, G. (2004). The evolution of brain lateralization: a game-theoretical analysis of population structure. Proc. Biol. Sci. 271, 853-857. doi: 10.1098/rspb.2003.2669

Gibson, J. B. (1973). Intelligence and handedness. Nature 243, 482-482. doi: $10.1038 / 243482 \mathrm{~b} 0$

Giljov, A., Karenina, K., and Malashichev, Y. (2018). Facing each other: mammal mothers and infants prefer the position favoring right hemisphere processing. Biol. Lett. 14:20170707. doi: 10.1098/rsbl.2017.0707

Gottlieb, G. (1991). Experiential canalization of behavioral development: theory. Dev. Psychol. 27, 4-13. doi: 10.1037/0012-1649.27.1.4

Groothuis, T. G. G., McManus, I. C., Schaafsma, S. M., and Geuze, R. H. (2013). The fighting hypothesis in combat: how well does the fighting hypothesis explain human left-handed minorities? Ann. N Y Acad. Sci. 1288, 100-109. doi: $10.1111 /$ nyas.12164

Gubernick, D. J. (2013). Parental Care in Mammals. Berlin/Heidelberg: Springer Science + Business Media.

Guiard, Y. (1987). Asymmetric division of labor in human skilled bimanual action. J. Mot. Behav. 19, 486-517. doi: 10.1080/00222895.1987.10735426

Güntürkün, O., and Ocklenburg, S. (2017). Ontogenesis of lateralization. Neuron 94, 249-263. doi: 10.1016/j.neuron.2017.02.045

Harris, L. J., Almerigi, J. B., Carbary, T. J., and Fogel, T. G. (2001). Left-side infant holding: a test of the hemispheric arousal-attentional hypothesis. Brain Cogn. 46, 159-165. doi: 10.1016/s0278-2626(01)80056-7

Harris, L. J., Almerigi, J. B., and Kirsch, E. A. (2000). Side preference in adults for holding infants: contributions of sex and handedness in a test of imagination. Brain Cogn. 43, 246-252.

Harris, L. J., Cárdenas, R. A., Spradlin, M. P., and Almerigi, J. B. (2010). Why are infants held on the left? A test of the attention hypothesis with a doll, a book and a bag. Laterality 15, 548-571. doi: 10.1080/13576500903064018

Hendriks, A. W., van Rijswijk, M., and Omtzigt, D. (2011). Holding-side influences on infant's view of mother's face. Laterality 16, 641-655. doi: 10.1080/13576500903468904

Hepper, P. G. (2013). The developmental origins of laterality: fetal handedness. Dev. Psychobiol. 55, 588-595. doi: 10.1002/dev.21119

Hepper, P. G., Shahidullah, S., and White, R. (1990). Origins of fetal handedness. Nature 347:431. doi: 10.1038/347431b0

Herdien, L., Malcolm-Smith, S., and Pileggi, L.-A. (2020). Leftward cradling bias in males and its relation to autistic traits and lateralised emotion processing. Brain Cogn. 147:105652. doi: 10.1016/j.bandc.2020.105652

Hopkins, W. D. (2004). laterality in maternal cradling and infant positional biases: implications for the development and evolution of hand preferences in nonhuman primates. Int. J. Primatol. 25, 1243-1265. doi: 10.1023/B:IJOP. $0000043961.89133 .3 \mathrm{~d}$

Iidaka, T., Sadato, N., Yamada, H., and Yonekura, Y. (2000). Functional asymmetry of human prefrontal cortex in verbal and non-verbal episodic memory as revealed by fMRI. Cogn. Brain Res. 9, 73-83. doi: 10.1016/s09266410(99)00047-6

Isles, A. R., Ingason, A., Lowther, C., Walters, J., Gawlick, M., Stöber, G., et al. (2016). Parental origin of interstitial duplications at 15q11.2-q13.3 in schizophrenia and neurodevelopmental disorders. PLoS Genet. 12:e1005993. doi: 10.1371/journal.pgen.1005993

Johnston, D. W., Nicholls, M. E. R., Shah, M., and Shields, M. A. (2009). Nature's experiment? Handedness and early childhood development. Demography 46, 281-301. doi: 10.1353/dem.0.0053

Jones, S. (2014). Maternal cradling bias and early communicative interactions: implications for early identification of children at risk. Infant Behav. Dev. 37, 722-728. doi: 10.1016/j.infbeh.2014.08.008

Karenina, K., Giljov, A., Ingram, J., Rowntree, V. J., and Malashichev, Y. (2017). Lateralization of mother-infant interactions in a diverse range of mammal species. Nat. Ecol. Evol. 1:30. doi: 10.1038/s41559016-0030

Kleck, R. E., and Mendolia, M. (1990). Decoding of profile versus full-face expressions of affect. J. Nonverbal Behav. 14, 35-49. doi: 10.1007/bf01006578

Kobyliansky, E., and Micle, S. (1986). Handedness and dermatoglyphic directional and fluctuating asymmetry. Z. Morphol. Anthropol. 76, 313-329.

Leach, E. L., Prefontaine, G., Hurd, P. L., and Crespi, B. J. (2014). The imprinted gene LRRTM1 mediates schizotypy and handedness in a nonclinical population. J. Hum. Genet. 59, 332-336. doi: 10.1038/jhg.2014.30 
Leblanc, R. (2017). Fearful Asymmetry: Bouillaud, Dax, Broca and the Localization of Language, Paris, 1825-1879. Montreal, QC: McGill-Queen's Press.

Levy, J., Heller, W., Banich, M. T., and Burton, L. A. (1983). Asymmetry of perception in free viewing of chimeric faces. Brain Cogn. 2, 404-419. doi: 10.1016/0278-2626(83)90021-0

Lucafò, C., Marzoli, D., Prete, G., and Tommasi, L. (2016). Laterality effects in the spinning dancer illusion: the viewing-from-above bias is only part of the story. Br. J. Psychol. 107, 698-709. doi: 10.1111/bjop.12166

Lucafò, C., Marzoli, D., Zdybek, P., Malatesta, G., Smerilli, F., Ferrara, C., et al. (2021). The bias toward the right side of others is stronger for hands than for feet. Symmetry 13:146. doi: 10.3390/sym13010146

Maestripieri, D., and Mateo, J. M. (2009). Maternal Effects in Mammals. Chicago, IL: University of Chicago Press.

Malatesta, G., Marzoli, D., Apicella, F., Abiuso, C., Muratori, F., Forrester, G. S., et al. (2020a). Received cradling bias during the first year of life: a retrospective study on children with typical and atypical development. Front. Psychiatry 11:91. doi: 10.3389/fpsyt.2020.00091

Malatesta, G., Marzoli, D., Morelli, L., Pivetti, M., and Tommasi, L. (2020b). The role of ethnic prejudice in the modulation of cradling lateralization. J. Nonverbal. Behav. doi: 10.1007/s10919-020-00346-y. [Epub ahead of print].

Malatesta, G., Marzoli, D., and Tommasi, L. (2020c). Keep a left profile, baby! The left-cradling bias is associated with a preference for left-facing profiles of human babies. Symmetry 12:911. doi: 10.3390/sym120 60911

Malatesta, G., Marzoli, D., and Tommasi, L. (2020d). The association between received maternal cradling and neurodevelopment: is left better? Med. Hypotheses 134:109442. doi: 10.1016/j.mehy.2019.109442

Malatesta, G., Marzoli, D., Piccioni, C., and Tommasi, L. (2019a). The relationship between the left-cradling bias and attachment to parents and partner. Evol. Psychol. 17:1474704919848117. doi: 10.1177/14747049198 48117

Malatesta, G., Marzoli, D., Rapino, M., and Tommasi, L. (2019b). The left-cradling bias and its relationship with empathy and depression. Sci. Rep. 9:6141. doi: 10.1038/s41598-019-42539-6

Manning, J. T. (1991). Sex differences in left-side infant holding: results from "family album" photographs. Ethol. Sociobiol. 12, 337-343. doi: 10.1016/01623095(91)90029-P

Manning, J. T., and Chamberlain, A. T. (1991). Left-side cradling and brain lateralization. Ethol. Sociobiol. 12, 237-244. doi: 10.1016/0162-3095(91)90006-c

Manning, J. T., and Denman, J. (1994). Lateral cradling preferences in humans (Homo sapiens): similarities within families. J. Comp. Psychol. 108, 262-265. doi: 10.1037/0735-7036.108.3.262

Manning, J. T., Heaton, R., and Chamberlain, A. T. (1994). Left-side cradling: similarities and differences between apes and humans. J. Hum. Evol. 26, 77-83. doi: 10.1006/jhev.1994.1005

Manning, J. T., Trivers, R. L., Thorhill, R., Singh, D., Denman, J., Eklo, M. H., et al. (1997). Ear asymmetry and left-side cradling. Evol. Hum. Behav. 18, 327-340. doi: 10.1016/s1090-5138(97)00043-3

Marzoli, D., Lucafò, C., Pagliara, A., Cappuccio, R., Brancucci, A., and Tommasi, L. (2015). Both right- and left-handers show a bias to attend others' right arm. Exp. Brain Res. 233, 415-424. doi: 10.1007/s00221-014-4124-5

Marzoli, D., Lucafò, C., Rescigno, C., Mussini, E., Padulo, C., Prete, G., et al. (2017a). Sex-specific effects of posture on the attribution of handedness to an imagined agent. Exp. Brain Res. 235, 1163-1171. doi: 10.1007/s00221-0174886-7

Marzoli, D., Pagliara, A., Prete, G., Malatesta, G., Lucafò, C., Padulo, C., et al. (2017b). Hemispheric asymmetries in the processing of body sides: a study with ambiguous human silhouettes. Neurosci. Lett. 656, 114-119. doi: 10.1016/j. neulet.2017.07.027

Marzoli, D., Menditto, S., Lucafò, C., and Tommasi, L. (2013). Imagining others' handedness: visual and motor processes in the attribution of the dominant hand to an imagined agent. Exp. Brain Res. 229, 37-46. doi: 10.1007/s00221013-3587-0

Marzoli, D., Mitaritonna, A., Moretto, F., Carluccio, P., and Tommasi, L. (2011a). The handedness of imagined bodies in action and the role of perspective taking. Brain Cogn. 75, 51-59. doi: 10.1016/j.bandc.2010.10.002

Marzoli, D., Palumbo, R., Di Domenico, A., Penolazzi, B., Garganese, P., and Tommasi, L. (2011b). The relation between self-reported empathy and motor identification with imagined agents. PLoS One 6:e14595. doi: 10.1371/journal. pone. 0014595

Marzoli, D., Pagliara, A., Prete, G., Malatesta, G., Lucafò, C., Padulo, C., et al. (2019). Lateralized embodiment of ambiguous human silhouettes: data on sex differences. Data Brief 25:104009. doi: 10.1016/j.dib.2019.104009

Marzoli, D., Prete, G., and Tommasi, L. (2014). Perceptual asymmetries and handedness: a neglected link? Front. Psychol. 5:163. doi: 10.3389/fpsyg.2014. 00163

Marzoli, D., and Tommasi, L. (2009). Side biases in humans (Homo sapiens): three ecological studies on hemispheric asymmetries. Naturwissenschaften 96 , 1099-1106. doi: 10.1007/s00114-009-0571-4

McManus, C. (2002). Right Hand, Left Hand: The Origins of Asymmetry in Brains, Bodies, Atoms and Cultures. Cambridge, MA: Harvard University Press.

McManus, C. (2019). Half a century of handedness research: myths, truths; fictions, facts; backwards, but mostly forwards. Brain Neurosci. Adv. 3:2398212818820513. doi: 10.1177/2398212818820513

McManus, I. C., Davison, A., and Armour, J. A. L. (2013). Multilocus genetic models of handedness closely resemble single-locus models in explaining family data and are compatible with genome-wide association studies. Ann. N Y Acad. Sci. 1288, 48-58. doi: 10.1111/nyas.12102

Medland, S. E., Duffy, D. L., Wright, M. J., Geffen, G. M., Hay, D. A., Levy, F., et al. (2009). Genetic influences on handedness: data from 25,732 Australian and Dutch twin families. Neuropsychologia 47, 330-337. doi: 10.1016/j. neuropsychologia.2008.09.005

Mendolia, M., and Kleck, R. E. (1991). Watching people talk about their emotions: inferences in response to full-face vs. profile expressions. Motiv. Emot. 15, 229-242. doi: 10.1007/bf00995644

Michel, G. F., Babik, I., Nelson, E. L., Campbell, J. M., and Marcinowski, E. C. (2018). Evolution and development of handedness: an Evo-Devo approach. Prog. Brain Res. 238, 347-374. doi: 10.1016/bs.pbr.2018.06.007

Michel, G. F., and Harkins, D. A. (1986). Postural and lateral asymmetries in the ontogeny of handedness during infancy. Dev. Psychobiol. 19, 247-258. doi: $10.1002 / \mathrm{dev} .420190310$

Nicholls, M. E. R., Chapman, H. L., Loetscher, T., and Grimshaw, G. M. (2010). The relationship between hand preference, hand performance and general cognitive ability. J. Int. Neuropsychol. Soc. 16, 585-592. doi: $10.1017 /$ S1355617710000184

Norholt, H. (2020). Revisiting the roots of attachment: a review of the biological and psychological effects of maternal skin-to-skin contact and carrying of full-term infants. Infant Behav. Dev. 60:101441. doi: 10.1016/j.infbeh.2020. 101441

Ocklenburg, S., Bürger, C., Westermann, C., Schneider, D., Biedermann, H., and Güntürkün, O. (2010). Visual experience affects handedness. Behav. Brain Res. 207, 447-451. doi: 10.1016/j.bbr.2009.10.036

Ocklenburg, S., Packheiser, J., Schmitz, J., Rook, N., Güntürkün, O., Peterburs, J., et al. (2018). Hugs and kisses-the role of motor preferences and emotional lateralization for hemispheric asymmetries in human social touch. Neurosci. Biobehav. Rev. 95, 353-360. doi: 10.1016/j.neubiorev.2018.10.007

Ocklenburg, S., Schmitz, J., Moinfar, Z., Moser, D., Klose, R., Lor, S., et al. (2017). Epigenetic regulation of lateralized fetal spinal gene expression underlies hemispheric asymmetries. eLife 6:e22784. doi: 10.7554/eLife. 22784

Packheiser, J., Rook, N., Dursun, Z., Mesenhöller, J., Wenglorz, A., Güntürkün, O., et al. (2019a). Embracing your emotions: affective state impacts lateralisation of human embraces. Psychol. Res. 83, 26-36. doi: 10.1007/s00426-018 -0985-8

Packheiser, J., Schmitz, J., Berretz, G., Papadatou-Pastou, M., and Ocklenburg, S. (2019b). Handedness and sex effects on lateral biases in human cradling: three meta-analyses. Neurosci. Biobehav. Rev. 104, 30-42. doi: 10.1016/j.neubiorev. 2019.06.035

Packheiser, J., Schmitz, J., Berretz, G., Carey, D. P., Paracchini, S., PapadatouPastou, M., et al. (2020a). Four meta-analyses across 164 studies on atypical footedness prevalence and its relation to handedness. Sci. Rep. 10:14501. doi: 10.1038/s41598-020-71478-w

Packheiser, J., Schmitz, J., Metzen, D., Reinke, P., Radtke, F., Friedrich, P., et al. (2020b). Asymmetries in social touch-motor and emotional biases on lateral preferences in embracing, cradling and kissing. Laterality 25, 325-348. doi: 10.1080/1357650X.2019.1690496 
Packheiser, J., Schmitz, J., Pan, Y., El Basbasse, Y., Friedrich, P., Güntürkün, O., et al. (2020c). Using mobile EEG to investigate alpha and beta asymmetries during hand foot use. Front. Neurosci. 14:109. doi: 10.3389/fnins.2020.00109

Papadatou-Pastou, M., and Tomprou, D.-M. (2015). Intelligence and handedness: meta-analyses of studies on intellectually disabled, typically developing, and gifted individuals. Neurosci. Biobehav. Rev. 56, 151-165. doi: 10.1016/j. neubiorev.2015.06.017

Parente, R., and Tommasi, L. (2008). A bias for the female face in the right hemisphere. Laterality 13, 374-386. doi: 10.1080/13576500802103495

Penolazzi, B., Di Domenico, A., Marzoli, D., Mammarella, N., Fairfield, B., Franciotti, R., et al. (2010). Effects of transcranial Direct Current Stimulation on episodic memory related to emotional visual stimuli. PLoS One 5:e10623. doi: 10.1371/journal.pone.0010623

Pileggi, L.-A., Malcolm-Smith, S., and Solms, M. (2015). Investigating the role of social-affective attachment processes in cradling bias: the absence of cradling bias in children with autism spectrum disorders. Laterality 20, 154-170. doi: 10.1080/1357650X.2014.948449

Pileggi, L.-A., Storey, S., and Malcolm-Smith, S. (2020). Depressive symptoms disrupt leftward cradling. J. Child Adolesc. Ment. Health 32, 35-43. doi: 10.2989/17280583.2020.1765786

Prete, G., Capotosto, P., Zappasodi, F., and Tommasi, L. (2018a). Contrasting hemispheric asymmetries for emotional processing from event-related potentials and behavioral responses. Neuropsychology 32, 317-328. doi: 10.1037/neu0000443

Prete, G., D’Anselmo, A., Brancucci, A., and Tommasi, L. (2018b). Evidence of a Right Ear Advantage in the absence of auditory targets. Sci. Rep. 8:15569. doi: 10.1038/s41598-018-34086-3

Prete, G., Capotosto, P., Zappasodi, F., Laeng, B., and Tommasi, L. (2015a). The cerebral correlates of subliminal emotions: an electroencephalographic study with emotional hybrid faces. Eur. J. Neurosci. 42, 2952-2962. doi: 10.1111/ejn. 13078

Prete, G., D’Ascenzo, S., Laeng, B., Fabri, M., Foschi, N., and Tommasi, L. (2015b). Conscious and unconscious processing of facial expressions: evidence from two split-brain patients. J. Neuropsychol. 9, 45-63. doi: 10.1111/jnp. 12034

Prete, G., Laeng, B., Fabri, M., Foschi, N., and Tommasi, L. (2015c). Right hemisphere or valence hypothesis, or both? The processing of hybrid faces in the intact and callosotomized brain. Neuropsychologia 68, 94-106. doi: 10.1016/j.neuropsychologia.2015.01.002

Prete, G., Marzoli, D., and Tommasi, L. (2015d). Upright or inverted, entire or exploded: right-hemispheric superiority in face recognition withstands multiple spatial manipulations. PeerJ 3:e1456. doi: 10.7717/ peerj. 1456

Prete, G., Fabri, M., Foschi, N., and Tommasi, L. (2016a). Face gender categorization and hemispheric asymmetries: contrasting evidence from connected and disconnected brains. Neuroscience 339, 210-218. doi: 10.1016/j. neuroscience.2016.10.021

Prete, G., Marzoli, D., Brancucci, A., and Tommasi, L. (2016b). Hearing it right: evidence of hemispheric lateralization in auditory imagery. Hear. Res. 332, 80-86. doi: 10.1016/j.heares.2015.12.011

Prete, G., Fabri, M., Foschi, N., and Tommasi, L. (2020a). Voice gender categorization in the connected and disconnected hemispheres. Soc. Neurosci. 15, 385-397. doi: 10.1080/17470919.2020.1734654

Prete, G., Tommasi, V., and Tommasi, L. (2020b). Right news, good news! The valence hypothesis and hemispheric asymmetries in auditory imagery. Lang. Cogn. Neurosci. 35, 409-419. doi: 10.1080/23273798.2019.1659990

Prete, G., Laeng, B., and Tommasi, L. (2014a). Lateralized hybrid faces: evidence of a valence-specific bias in the processing of implicit emotions. Laterality 19, 439-454. doi: 10.1080/1357650X.2013.862255

Prete, G., Marzoli, D., Brancucci, A., Fabri, M., Foschi, N., and Tommasi, L. (2014b). The processing of chimeric and dichotic emotional stimuli by connected and disconnected cerebral hemispheres. Behav. Brain Res. 271, 354-364. doi: 10.1016/j.bbr.2014.06.034

Prete, G., Malatesta, G., and Tommasi, L. (2017). Facial gender and hemispheric asymmetries: a hf-tRNS study. Brain Stimul. 10, 1145-1147. doi: 10.1016/j.brs. 2017.08.002

Prete, G., and Tommasi, L. (2018). Split-brain patients: visual biases for faces. Prog. Brain Res. 238, 271-291. doi: 10.1016/bs.pbr.2018.06.006
Previc, F. H. (1991). A general theory concerning the prenatal origins of cerebral lateralization in humans. Psychol. Rev. 98, 299-334. doi: 10.1037/0033-295x.98. 3.299

Reissland, N., Hopkins, B., Helms, P., and Williams, B. (2009). Maternal stress and depression and the lateralisation of infant cradling. J. Child Psychol. Psychiatry 50, 263-269. doi: 10.1111/j.1469-7610.2007.01791.x

Ruta, L., Mazzone, D., Mazzone, L., Wheelwright, S., and Baron-Cohen, S. (2012). The autism-spectrum quotient-italian version: a cross-cultural confirmation of the broader autism phenotype. J. Autism Dev. Disord. 42, 625-633. doi: 10.1007/s10803-011-1290-1

Schmitz, J., Metz, G. A. S., Güntürkün, O., and Ocklenburg, S. (2017). Beyond the genome-towards an epigenetic understanding of handedness ontogenesis. Prog. Neurobiol. 159, 69-89. doi: 10.1016/j.pneurobio.2017.10.005

Scola, C., Arciszewski, T., Measelle, J., and Vauclair, J. (2013). Infant-holding bias variations in mother-child relationships: a longitudinal study. Eur. J. Dev. Psychol. 10, 707-722. doi: 10.1080/17405629.2013.791230

Scola, C., and Vauclair, J. (2010). Is infant holding-side bias related to motor asymmetries in mother and child? Dev. Psychobiol. 52, 475-486. doi: 10.1002/dev.20450

Serrien, D. J., and Sovijärvi-Spapé, M. M. (2015). Hemispheric asymmetries and the control of motor sequences. Behav. Brain Res. 283, 30-36. doi: 10.1016/j. bbr.2015.01.021

Simpson, J. A., and Belsky, J. (2008). "Attachment theory within a modern evolutionary framework," in Handbook of Attachment: Theory, Research, and Clinical Applications, 2nd edition (New York, NY: The Guilford Press), 131-157.

Somers, M., Shields, L. S., Boks, M. P., Kahn, R. S., and Sommer, I. E. (2015). Cognitive benefits of right-handedness: a meta-analysis. Neurosci. Biobehav. Rev. 51, 48-63. doi: 10.1016/j.neubiorev.2015.01.003

Strenze, T. (2007). Intelligence and socioeconomic success: a meta-analytic review of longitudinal research. Intelligence 35, 401-426. doi: 10.1016/j.intell.2006. 09.004

Stroganova, T. A., Nygren, G., Tsetlin, M. M., Posikera, I. N., Gillberg, C., Elam, M., et al. (2007). Abnormal EEG lateralization in boys with autism. Clin. Neurophysiol. 118, 1842-1854. doi: 10.1016/j.clinph.2007. 05.005

Suter, S. E., Huggenberger, H. J., Blumenthal, T. D., and Schachinger, H. (2011). Differential effect of ill-being and chronic stress on cradling behavior of first and multi-time parents. Infant Behav. Dev. 34, 170-178. doi: 10.1016/j.infbeh. 2010.12.003

Suter, S. E., Huggenberger, H. J., and Schächinger, H. (2007). Cold pressor stress reduces left cradling preference in nulliparous human females. Stress 10, 45-51. doi: 10.1080/10253890601141259

Thoma, R. J., Yeo, R. A., Gangestad, S. W., Lewine, J. D., and Davis, J. T. (2002). Fluctuating asymmetry and the human brain. Laterality 7, 45-58. doi: 10.1080/13576500143000122

Todd, B. K., and Banerjee, R. (2016). Lateralization of infant holding by mothers: a longitudinal evaluation of variations over the first 12 weeks. Laterality 21 , 12-33. doi: 10.1080/1357650X.2015.1059434

Tommasi, L. (2009). Mechanisms and functions of brain and behavioral asymmetries. Philos. Trans. R. Soc. Lond. B Biol. Sci. 364, 855-859. doi: $10.1098 /$ rstb.2008.0293

Tordjman, S. (2008). Reunifying autism and early-onset schizophrenia in terms of social communication disorders. Behav. Brain Sci. 31, 278-279. doi: 10.1017/s0140525x08004391

Tran, U. S., Stieger, S., and Voracek, M. (2014). Evidence for general right-, mixed-, and left-sidedness in self-reported handedness, footedness, eyedness, and earedness, and a primacy of footedness in a large-sample latent variable analysis. Neuropsychologia 62, 220-232. doi: 10.1016/j.neuropsychologia.2014. 07.027

Vervloed, M. P. J., Hendriks, A. W., and van den Eijnde, E. (2011). The effects of mothers' past infant-holding preferences on their adult children's face processing lateralisation. Brain Cogn. 75, 248-254. doi: 10.1016/j.bandc.2011. 01.002

Weatherill, R. P., Almerigi, J. B., Levendosky, A. A., Bogat, G. A., von Eye, A., and Harris, L. J. (2004). Is maternal depression related to side of infant holding? Int. J. Behav. Dev. 28, 421-427. doi: 10.1080/0165025044 4000117 
Wiberg, A., Ng, M., Al Omran, Y., Alfaro-Almagro, F., McCarthy, P., Marchini, J., et al. (2019). Handedness, language areas and neuropsychiatric diseases: insights from brain imaging and genetics. Brain 142, 2938-2947. doi: 10.1093/brain/awz257

Wyczesany, M., Capotosto, P., Zappasodi, F., and Prete, G. (2018). Hemispheric asymmetries and emotions: evidence from effective connectivity. Neuropsychologia 121, 98-105. doi: 10.1016/j.neuropsychologia.2018. 10.007

Yamaguchi, S., Yamagata, S., and Kobayashi, S. (2000). Cerebral asymmetry of the "top-down" allocation of attention to global and local features. J. Neurosci. 20:RC72. doi: 10.1523/JNEUROSCI.20-09-j0002.2000
Conflict of Interest: The authors declare that the research was conducted in the absence of any commercial or financial relationships that could be construed as a potential conflict of interest.

Copyright (c) 2021 Malatesta, Marzoli, Prete and Tommasi. This is an open-access article distributed under the terms of the Creative Commons Attribution License (CC BY). The use, distribution or reproduction in other forums is permitted, provided the original author(s) and the copyright owner(s) are credited and that the original publication in this journal is cited, in accordance with accepted academic practice. No use, distribution or reproduction is permitted which does not comply with these terms. 